\title{
MULTI-BASELINE INTERFEROMETRIC SIDE SCAN SONAR FOR THE CONSTRUCTION OF HIGH-PRECISION BATHYMETRY
}

\section{Roman O. Boldinov, Anatoly V. Sknarya}

V. Tikhomirov Scientific Research Institute of Instrument Design, https://niip.ru

Zhukovsky 140180, Moscow Region, Russian Federation

boldinov@mail.ru, sknarya.a@otd301.niip.ru

Abstract. Some results of processing data obtained with the help of multi-base interferometric sonar during its full-scale tests are presented. The possibility of reconstructing depths with the help of a multi-base interferometric sonar sonar with an accuracy not worse than $2 \%$ of the depth at the subterranean point is shown, which meets the requirements of the 5 th edition of the International Hydrographic Organization Standard S-44.

Keywords: sonar, single-baseline and multi-baseline interferometry, bathymetry

UDC 621.396.96

Bibliography - 9 references

Received 24.08.2018

RENSIT, 2018, 10(2):213-216

DOI: $10.17725 /$ rensit.2018.10.213

\section{Content}

1. INTRODUCTION (213)

2. Materials and methods (214)

3. Results (214)

4. Discussion (215)

5. Conclusion (216)

REFERENCES (216)

\section{INTRODUCTION}

Recently, the development of technical capabilities to build modern side-scan sonar (HBS) has made it possible to obtain acoustic images of the bottom surface of high quality. But a further increase in the informativeness of the acoustic study of the bottom surface is associated with the development of technology and techniques for obtaining a detailed relief and the formation of a three-dimensional image of the bottom surface. Therefore, to date, the task of creating technologies and hydroacoustic complexes capable of forming, in addition to acoustic images, also high-resolution and high resolution images, is also topical. This task is able to solve, in particular, interferometric side scan sonar (ISSS) [1].

The history of ISSS development has been on for several decades and all this time the system has been constantly developing and improving.

And here it should be specially noted that very many successes in the field of achievements in modern sonar were laid back in the twentieth century and were based on the achievements in the field of interplanetary radiolocation, a vivid representative of which was Academician V.A. Kotelnikov. It is the use of many achievements in the field of interplanetary radar that made it possible, even then, and now to successfully solve many problems. And the development of domestic ISSS refers to such tasks.

Improvement of ISSS was carried out due to constant competition with multibeam echosounder in solving the problem of constructing the bottom relief. Both data systems have both positive and negative qualities.

The shortcomings of the "standard" ISSS should first of all be attributed to the low accuracy of depth measurements in areas with a special form of the bottom relief, namely, for sharp jumps and depth differences. The relief with such geometry is mainly manifested in the survey of shelf zones of marine areas with underwater mountain relief, as well as in monitoring the state of underwater structures. The accuracy of the restoration of depths in such areas of the bottom surface, in most cases, is unsuitable for hydrographic use.

A few publications on this topic do not answer the above problem of improving the accuracy of depth measurements.

The purpose of this work is to develop a system that allows not only to make an area survey and threedimensional mapping of the bottom surface, but also to improve the accuracy of depth measurements using methods based on the statistical theory of radio engineering systems, probability theory and random 
processes, optimal filtering theory, and laboratory studies and full-scale tests.

\section{MATERIALS AND METHODS}

The geometry of the sight of the classical one-way interferometer sonar of the lateral view is shown in Fig. 1.

The interferometer consists of one transceiver (A2) and one receiver (A1) antennas, the angle of deviation of the interferometer base $\mathrm{B}$ from the vertical is $\beta$, and the viewing angle to the object on the bottom surface is $\alpha$. The required depth at the point $₹$ is $G=H-$ \%:

The principle of the ISSS operation is based on finding the phase difference between two signals reflected from the same resolution element on the bottom surface and received by two spaced-apart receive antennas. The phase difference found is the basis for constructing the relief of the investigated bottom section $[2,3]$.

If the ray path difference is denoted by $\Delta R=R_{1}$ - $R_{2}$, where $R_{1}=c_{s} \cdot \tau_{1} / 2$ и $R_{2}=c_{s} \cdot \tau_{2} / 2\left(c_{s}\right.$ is the sound velocity in the water medium), then the expression for the interferometric phase difference (IPD) of the two signals view:

$\Delta \varphi=2 \pi\left(R_{1}-R_{2}\right) / \lambda=2 \pi \Delta R / \lambda$,

where $\lambda$ is the wavelength.

Omitting a number of mathematical transformations, we obtain the final depth to the point $P[2]$ :

$G_{0}=R_{1}\left[\sqrt{1-\frac{R_{1}^{2}+B^{2}-\left(R_{1}-\frac{\lambda \Delta \varphi}{2 \pi}\right)^{2}}{2 B R_{1}}}-\cos (\beta) \frac{R_{1}^{2}+B^{2}-\left(R_{1}-\frac{\lambda \Delta \varphi}{2 \pi}\right)^{2}}{2 B R_{1}}\right]$.

Expression (2) defines a unique relationship between the depth to the resolution element on the bottom surface, the IPD, the base $B$ and the oblique range $R_{1}$.

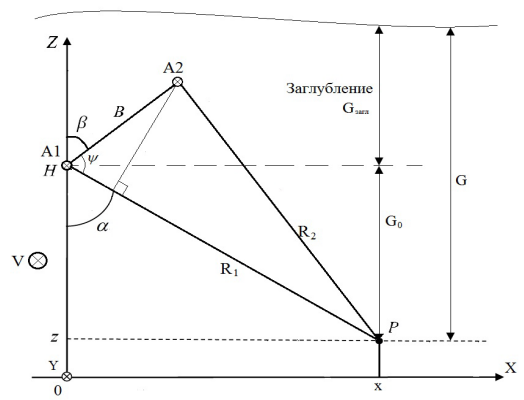

Fig. 1. Geometry of the bottom surface survey.

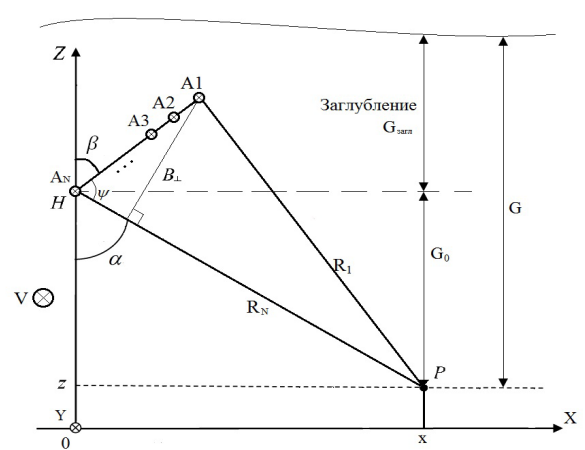

Fig. 2. Geometry of the bottom surface survey of multi-base ISSS.

It was the "standard" ISS that became the prototype in the development of its new modification, the multi-base ISS.

The features of the geometry of the bottom surface survey with a multi-base interferometric side scan sonar (MISSS) consisting of one transceiver (A1) and N-1 receiving (A2-AN) antennas are shown in Fig. 2. The angle of deviation of the base plane In the interferometer from the vertical is $\beta$, the angle of sight to the object on the surface of the bottom (resolution element) is $\alpha$.

The process of processing echoes in a multibase ISS can be represented in the form of a block diagram, shown in Fig. 3.

In the block diagram of Fig. 3: AS - the aerial switch; TM - transmitter; RX1 is the receiving path of the first receiving channel; $\mathrm{Rx} \mathrm{N}$ is the receiving path of the $\mathrm{N}$-th receiving channel; IPD is the interferometric phase difference.

\section{RESULTS}

Let us consider some processing steps, shown in Fig. 2 , in more detail on the example of data obtained during testing of the multi-base ISS mock-up at the V.V. Tikhomirov NIIP poligon.

The model of the multi-base ISS has the following characteristics: central frequency - 250

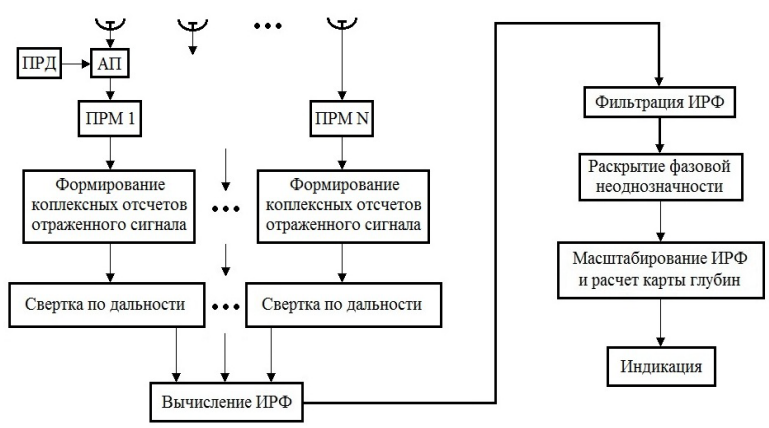

Fig. 3. Block diagram of the stages of echo-signals processing in a multi-base ISSS. 


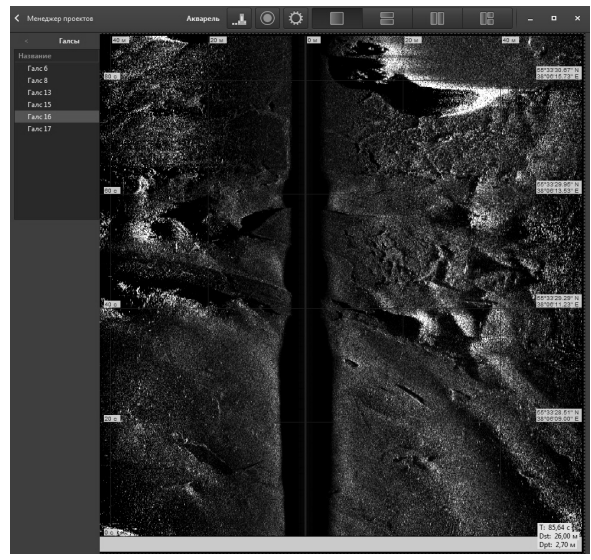

Fig. 4. Acoustic image from the 1st channel of the multi-base ISS.

$\mathrm{kHz}$; the width of the spectrum of the probe signal is $30 \mathrm{kHz}$; type of probing signal - chirp pulse; the duration of the probe pulse is from $3 \mathrm{~ms}$; the number of receiving antennas is 6 ; the maximum size of the antenna base is $2.5 \mathrm{~cm}$; angle of deviation of the base plane from the vertical - $30^{\circ}$; the width of the beam pattern of the radiating antenna along the azimuth is $1^{\circ}$.

In Fig. 4, by way of example, an acoustic image of the bottom surface obtained in real time after processing from the first channel of the multi-base ISS model is presented.

Antenna system of multi-base ISSS allows to form five interferograms corresponding to different antenna bases.

The most time-consuming stage of interferometric processing is the discovery of phase ambiguity (or "reversal" of the interferogram). The onset of phase ambiguity is due to the fact that the difference-phase values of the complex signal are calculated in the range $[-\pi, \pi]$, and the phase difference itself can vary by several such intervals. Therefore, to obtain information on relative depths, it is necessary to eliminate the phase ambiguity.

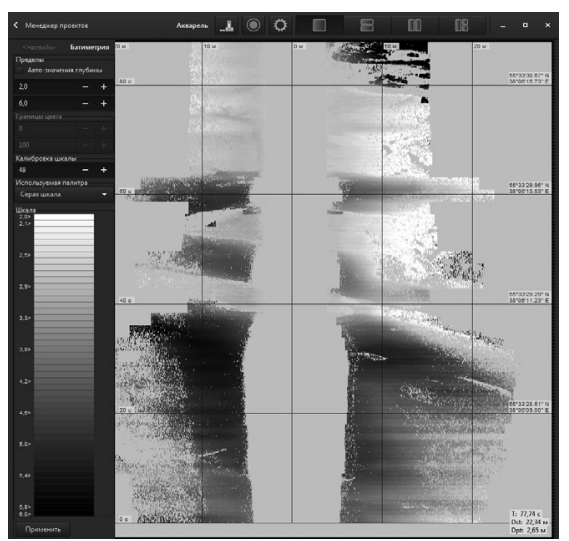

Fig. 5. Brightness image of the depth map.

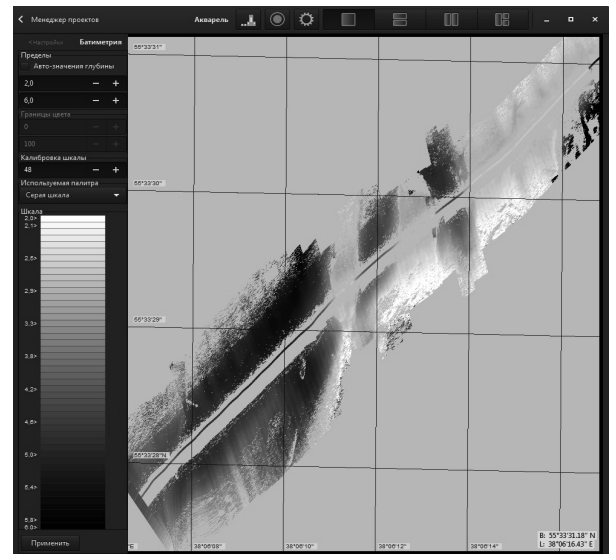

Fig. 6. Bright image of the depth map in geographical coordinates.

There are already several dozen methods for solving this problem [7]. Conventionally, they can be divided into two classes: local methods and global (integral) methods. For each class, there are solutions.

During the processing of data from the multibase ISSS, a multi-base ambiguity disclosure method [8] was used, using information from different interferograms. The use of this method makes it possible to increase the accuracy of calculating the "unfolded" difference-phase values, and consequently, the calculation of depths, and also to avoid the errors inherent in the typical single-base methods of uncovering ambiguity.

Below are some of the features of the software developed by the multi-base ISSS.

In Fig. 5 shows the brightness image of the depth map in real time of the bottom section from Fig. 4 in the coordinates of the range - the time of sounding.

In Fig. 6 shows the calculation of the depth map in real time of the bottom section of Fig. 4 in geographical coordinates.

In Fig. 7 shows a mosaic consisting of two intersecting depth maps, in geographic coordinates.

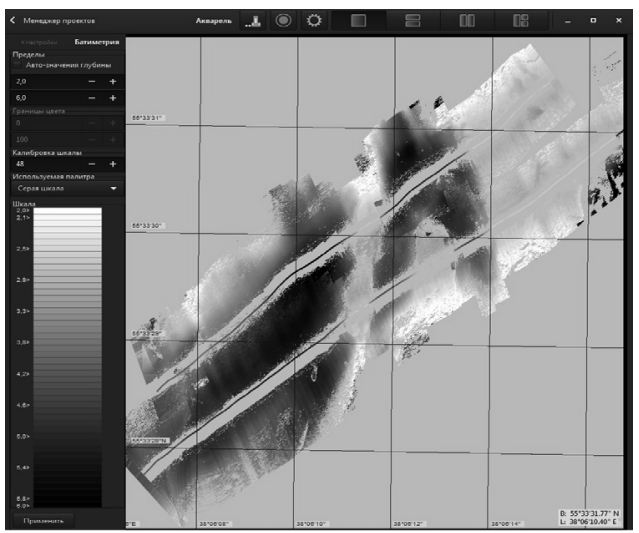

Fig. 7. Mosaics of 2 lines in geographical coordinates 


\section{DISCUSSION}

From Fig. 6, a significant correlation of depths with intersecting lines is visible. Also, within the study area, a depth measurement was made at the bottom by a single-beam echo sounder at the reference points. Further, a comparison was made of the depths obtained as a result of processing in a multibase ISSS and the depths obtained with the echosounder at the reference points. As a result, the accuracy of measuring depths in the zone of view not exceeding 3 depths was calculated, which turned out to be no worse than $2 \%(\sim 10 \mathrm{~cm})$ from the depth at the sub-point.

The received accuracy meets the requirements of the 5th edition of the International Hydrographic Organization's S-44 standard [9].

\section{CONCLUSION}

In the present paper the following results were obtained:

1. The review, analysis and justification of the requirements for modern and prospective sonar complexes designed to produce detailed three-dimensional images and high-precision formation of bathymetric depth maps are reviewed.

2. Algorithms for processing interferometric data in a multi-base interferometric lateral sonar are developed.

3. A model of a multi-base interferometric SSS has been developed.

4. The working capacity of the multi-base ISSS model was confirmed on the basis of actual data obtained during its full-scale tests. The possibility of reconstructing the depths during sharp changes in the relief with the help of a multibase interferometric SSS with an accuracy of at least $2 \%$ of the depth at the subterranean point is shown, which meets the requirements of the 5th edition of the International Hydrographic Organization Standard S-44.

5. A patent for the useful model "Interferometric sonar of lateral survey" was received (RF, 167401.2017.01.10) in January 2017.

\section{REFERENCES}

1. Richards MA. A beginners Guide to Interferometric SAR Concepts and Signal Processing. IEEE A\&E SYSTEMS MAGAZINE, 21(6)5-29.
2. Boldinov RO, Baskakov AI, Sknarya AV. Potentsial'naya tochnost' interferometricheskogo gidrolokatora bokovogo obzora. Vestnik MEI, 2016, 3:66-71.

3. Boldinov RO, Sknarya AV. K voprosu o primenenii algoritmov postroeniya rel'yefa dna $\mathrm{V}$ interferometricheskom gidrolokatore bokovogo obzora "NEMAN ISSS-500. Zhurnal Radioelektroniki, 2017, 2.

4. Rodriguez E, Martin JM. Theory and design of interferometric synthetic aperture radars. IEE Proceedings-F, 1992, 139(2):147-159.

5. Sintes C, Llort-Pujol G, Gueriot D. Coherent probabilistic error model for interferometricsidescan sonars. IEEE Journal of oceanic engineering, 2010, 35(2):412-423.

6. Kendall WB. Unambiguous accuracy of an interferometer angle-measuring system. IEEE Trans., 1965, SET-11(2):62-70.

7. Ghiglia DC, Pritt MD. Two-dimensional phase unwrapping. New York, Wilei, 1998.

8. You YN, Xu HP, Li JL, et al. Multi-baseline phase unwrapping via maximum likelihood phase gradient estimation. Proc. IGARSS, Quebec, Canada, 2014, pp. 374-377.

9. Strandart S-44 "Standarty MGO dlya s"emki rel'yefa morskogo dna" Mezhdunarodnoy gidrograficheskoy organizatsii (MGO), 5-ya redaktsiya. Monako, 2008, c. 17-18. 